\title{
Concepções de intelectual, reflexivo e pesquisador na formação dos professores de educação física
}

As políticas de formação inicial dos professores nas últimas décadas, veem sendo enfatizadas em diversos debates sobre educação em busca de qualificar o processo educativo, para melhor atingir os estudantes da educação básica no tocante as novas demandas sociais da contemporaneidade. Nesses debates, normalmente, é vinculado o sucesso das práticas educativas na formação inicial dos professores, tornando a formação docente o grande alvo das pesquisas acadêmicas. Assim, a formação de professores, etapa da constituição do profissional da educação, aparece sob várias formas e concepç̃̃es, e acabam sendo ligadas aos aportes teóricos dos seus formadores. O presente texto busca a partir de uma pesquisa bibliográfica de fundamentação teórica-metodológica ligada na perspectiva crítica histórico-cultural, a qual entende as atividades humanas como forma desencadeadora para o seu desenvolvimento, bem como tendo a educação como seu condicionante político e social, refletir sobre as concepções de intelectual, reflexivo e pesquisador na formação de professores, em especial para a Educação Física. Com sentido de contribuir epistemologicamente para o campo de formação inicial de professores na análise dos paradigmas de formação docente descritos pela literatura, esse estudo partiu das discussões realizadas na disciplina de questões epistemológicas da didática do ensino superior do curso de pós graduação em docência do ensino superior, na linha de formação de professores, currículo e ensino, tendo como campo de investigação científica à produção de novos conhecimentos na perspectiva interdisciplinar, propondo intervenções pedagógicas inovadoras para a transformação da sala de aula e da educação. Nessa perspectiva, pensar nos pressupostos da racionalidade técnica e o perfil do profissional formado sob esses parâmetros, são essenciais para compreender em qual âmbito de formação esse profissional se dará, para podermos agirmos sobre as teorias nas perspectivas de formar um profissional da educação reflexivo, e assim gerar as possibilidades de emancipação pela adoção de concepções na formação como pesquisa efetiva e permanente.

Palavras-chave: Formação de Professores; Concepções de Formação de Professores; Educação Física.

\section{Conceptions of intellectual, reflective and researcher in training physical education teachers}

\begin{abstract}
The policies of initial teacher education in the last decades have been emphasized in several debates about education in search of qualifying the educational process, to better reach the students of the basic education regarding the new social demands of the contemporaneity. In these debates, the success of educational practices in the initial formation of teachers is usually linked, making teacher education the major target of academic research. Thus, the formation of teachers, the stage of the constitution of the professional of education, appears under various forms and conceptions, and end up being linked to the theoretical contributions of their formators. The present text seeks from a bibliographical research of theoretical-methodological forms and conceptions, and end up being linked to the theoretical contributions of their formators. The present text seeks from a bibliographical research of theoretical-methodological
foundation linked in the historical-cultural critical perspective, which understands human activities as a trigger for its development, as well as having education as its political and social conditioning, reflect about the conceptions of intellectual, reflective and researcher in teacher education, especially for Physical Education. In order to contribute epistemologically to the field of initial teacher education in the analysis of the teacher education paradigms described in the literature, this study was based on discussions in the discipline of epistemological issue of higher education didactics of postgraduate teaching in higher education. , in line with teacher training, curriculum and teaching, having as a field of scientific research the production of new knowledge in an interdisciplinary perspective, proposing innovative pedagogical interventions for the transformation of the classroom and education. From this perspective, thinking about the assumptions of technical rationality and the profile of the professional trained under these parameters are essential to understand in which training context this professional will take place, so that we can act on the theories from the perspective of forming a reflective education professional, and thus generate the possibilities of emancipation through the adoption of conceptions in formation as effective and permanent research.
\end{abstract}

Keywords: Teacher Training; Teacher Training Concepts; Physical education.

Topic: Bases e Teorias Educacionais

Reviewed anonymously in the process of blind peer.
Received: $\mathbf{1 1 / 0 3 / 2 0 2 0}$

Approved: 10/05/2020
José de Caldas Simões Neto (iD

Centro Universitário Dr. Leão Sampaio, Brasil

http://lattes.cnpq.br/0470733825644726

http://orcid.org/0000-0003-1036-2315

ncaldas_22@hotmail.com

Raimundo Santana Leandro (ic)

Centro Universitário Dr. Leão Sampaio, Brasil

http://lattes.cnpq.br/5343749992705209

http://orcid.org/0000-0003-3186-3530

raileandro07@hotmail.com

Maria Dulcinea da Silva Loureiro (iD)

Universidade Regional do Cariri, Brasil

http://lattes.cnpq.br/4687440069986005

http://orcid.org/0000-0001-8964-8273

mdslou@uol.com.br
Ariza Maria Rocha (iD)

Universidade Regional do Cariri, Brasil

http://lattes.cnpq.br/3657678560716070

http://orcid.org/0000-0003-4706-8646

ariza.rocha@urca.br
Referencing this:

SIMÕES NETO, J. C.; LEANDRO, R. S.; LOUREIRO, M. D. S.; ROCHA, A. $M$.. Concepções de intelectual, reflexivo e pesquisador na formação dos professores de educação física. Educationis, v.8, n.2, p.1-7, 2020. DOI: http://doi.org/10.6008/CBPC2318-3047.2020.002.0001 


\section{INTRODUÇÃO}

Um dos paradigmas na formação de professores de Educação Física no Brasil que perduram até os dias atuais, está nos equívocos e interpretações das concepções epistemologias da área. Em que é demasiadamente pautada em uma formação técnica positivista, derivada do conhecimento científico, observados e produzidos nas relações sociais no interior do cotidiano dialético dos campos acadêmicos da Educação Física (BRACHT, 2000).

A Educação Física chega ao Brasil, com ideais ligadas na prática de exercícios gymnasticos, com objetivos voltados para a saúde e força do corpo, e os professores, ainda não tinham cursos formais de graduação, eram os instrutores das aulas. E mesmo com tantas transformações ao logo dos 108 anos, a contar da primeira escola brasileira de formação de profissionais de Educação Física, criada entre 1909 e 1910 pela Polícia Militar, a Escola de Educação Física da Força Pública do Estado de São Paulo até o presente ano de 2018, apesar de várias mudanças as concepções filosóficas e epistemológicas positivistas da formação dos profissionais ainda são visivelmente observadas em nossas salas de aulas.

$\mathrm{Na}$ atualizada frente as novas demandas sociais, em que a escola recebe, essas habilidades técnicas e positivistas dos conhecimentos, não são suficientemente adequadas para que o professor consiga compreender a realidade que o cerca, bem como para desenvolver as capacidades de apreender nas diferentes situações existentes nas relações professor-aluno, professor-escola e professor-sociedade.

Os professores que ainda exercem suas atividades com metodologias tradicionais e tecnicistas, possivelmente tiveram uma carência em suas formações para a relação e estímulos das capacidades críticas e reflexivas durante a sua formação inicial, em especial sobre o seu próprio papel na escola e sobre a realidade social, política, cultural e educacional que os cercam, essas práticas podem ser originadas de dificuldades oriundas de uma formação ainda pautada nas concepções positivistas. Podendo levar aos profissionais ao não reconhecimento dos signos e significados mais amplos das palavras do novo repertório educacional e das novas características econômicas, sociais e culturais dos estudantes, nos momentos de seleção, realização e desenvolvimento dos conteúdos e atividades e em especial na avaliação desses (RODRIGUES, 1998).

\section{METODOLOGIA}

O presente texto busca a partir de uma pesquisa bibliográfica, qualitativa de fundamentação teóricametodológica ligada na perspectiva crítica histórico-cultural da formação inicial de professores reflexivos, intelectuais e pesquisadores, em especial para a formação em Educação Física, buscando uma melhora da qualidade de sua ação docente. Sendo que ainda é muito visível dentro da sala de aula as concepções epistemológicas positivistas. Segundo Bachelard (1977, citado por TESSER, 1995), a epistemologia é uma história da ciência necessariamente histórica que visa a produção dos conhecimentos científicos sob os aspectos lógico, ideológico e histórico.

O conhecimento é uma obra temporal e para Habermas (1986), a epistemologia crítica deve 
interrogar os cientistas e os técnicos sobre sua responsabilidade social, procurando mostrar que o significado da ciência não está atrelado apenas no saber, mas também no poder que lhe confere. Para o autor não existe neutralidade cientifica, todo conhecimento tem um motivo, uma direção, um propósito e alguém que o dirige ou direciona. $\mathrm{O}$ autor ainda faz uma crítica as formas ingênuas do cientificismo positivista.

A epistemologia é uma reflexão profunda da ciência, pois a mesma possui lugar significativo na sociedade. Exercendo um papel de reflexão e critica, quando ela tenta mostrar aos cientistas suas filosofias implícitas nas ciências, quando ela submete a ciência a um estudo crítico, pois a ciência utilizada sem consciência torna-se a ruína da alma (TESSER, 1995).

A técnica utilizada foi a análise dos conteúdos que segundo Laurence (2011), é um conjunto de técnicas necessárias para descrição do conteúdo de mensagens permitindo a inferência de conhecimento relativo as condições de produção, podendo ser aplicada em diversos discursos e todas as formas de comunicação. O pesquisador busca entender características, estruturas e modelos que estão nos fragmentos da mensagem. Essa técnica se dispõe em três fazes: pré-análise, exploração do material e tratamento dos resultados; inferência e a interpretação.

A seleção dos textos foi feita nas diversas bases de dados: LILACS, SciELO, Google acadêmico. Após a revisão de literatura foram selecionados alguns autores de acordo com cada temática. Em que sobre o professor intelectual foi avaliado os autores Azevedo et al. (2006) e Giroux (1997) que exaltam a capacidade do professor de alinhar a teoria com a prática que como qualquer atividade humana o pensamento não se desprende da aplicação da prática. Sobre o professor reflexivo foram analisados os escritos de Contreras (2012) e Gómez et al. (1992), que definem a tarefa do professor de refletir sobre suas ações e mudar os rumos e conteúdo de uma atividade docente e que analisar o ambiente em que se encontra envolvendo na repetição. Para as concepções do professor pesquisador nos auxiliaram os escritos de Moreira (1995); Nóvoa (1992) e Rodrigues (2006), que afirmam quando o professor intelectual é reflexivo nas suas ações em sala de aula e consegue trazer novos elementos para sua ação docente, passa a ser um pesquisador de si mesmo, seu trabalho passa a ser transformador.

\section{DISCUSSÃO TEÓRICA}

\section{Refletindo sobre a formação de professores de educação física}

O conhecimento profissional sobre a prática docente, vem cada vez mais sendo desvalorizado, em especial pelo distanciamento e/ou equívocos existentes na compreensão entre teoria e prática, escola e universidade, pensamento e ação. No qual a formação docente, em especial de Educação Física, tende a 'preparar' o professor para o exercício - 'execução' - de atividades técnicas, e muitas vezes é deixado em segundo plano nessa formação, os elementos reflexivos, críticos, sociais, culturais e políticos nesse processo educativo de formação. Frente a esse debate Schön (1992) destaca que a crise de confiança no conhecimento profissional é desencadeada na tentativa de perceber a epistemologia da prática profissional, em que "na educação, esta crise centra-se num conflito entre o saber escolar e a reflexão-na-ação dos professores e 
alunos".

A reflexão não é determinada biológica ou psicologicamente, nem é pensamento puro, antes expressa uma orientação para a ação e refere-se às relações entre o pensamento e a ação nas situações históricas em que nos encontramos; não é uma forma individualista de trabalho mental, quer seja mecânica ou especulativa, pois depende das relações sociais; não é independente dos valores, nem neutra, pois expressa e serve interesses humanos, políticos culturais e sociais particulares; não é indiferente nem passiva perante a ordem social, nem propaga meramente valores sociais de consenso, pois reproduz ou transforma ativamente as práticas ideológicas que estão na base da ordem social; não é um processo mecânico, nem simplesmente um exercício criativo de construção de novas ideias, antes é uma prática que exprime o nosso poder para reconstruir a vida social, ao participar na comunicação, na tomada de decisões e na ação social. (KEMMIS, 1985, citado por NÓVOA, 1992)

A tomada de decisão do professor depende de uma reflexão também oriunda dos discentes, seus anseios, suas ideias, suas opiniões podem e devem mudar os rumos de uma aula. O exercício da atividade docente - 'dar aula' - não pode ser resumido a uma atividade técnica, o ato de ensinar, não pode ser aplicado como uma técnica, um método aplicável, um protocolo a ser seguido, uma receita de bolo pensada em medidas e passos exatos, pois nesse percurso o surgimento de situações e diversificados acontecimentos na aula ocorrem a todo instante. A capacidade do docente não é apenas encontrar respostas para essas variações, e sim compreender o problema em sua amplitude de acontecimentos, perceber os campos de origem, as causas e consequências das relações e pensamento envolvidos, assim, a capacidade de reflexão e crítica do docente deve ser pautado segundo Moreira (1995) "[...] na conversa-reflexiva-com-a-situação permitindo aos atores repensar a compreensão do que ocorre, refletir sobre suas perspectivas e procurar comunicá-las".

O exercício docente não pode ser limitado para a execução de ações e planejamentos elaborados por um sistema de 'terceirização', tendo o professor como um executor de ações/atividades. Pelo contrário, os professores (as) exercem um trabalho de intelectuais, devendo assumir as suas responsabilidades pedagógicas e políticas, que devem ser inerentes a sua formação e atuação enquanto ser intelectual e crítico, autônomo e criativo, em que se preocupa com os conhecimentos tratados pela Educação Física, pautados na cultura corporal do movimento, em conhecimentos mais emancipados e com significado para os sujeitos.

O professor intelectual pode ser caracterizado como "professor que expressa um pensamento crítico às injustiças e desigualdades sociais, mas é incapaz de deixar de se preocupar com suas particularidades de ordem pessoal para uma ação de ordem coletiva" (AZEVEDO et al., 2006). Vale ressaltar que esse conceito de intelectual parte das concepções de Gramsci, que procurar inserir na educação, essa atribuição a partir do conceito de intelectual orgânico, na relação dialética entre o termo conservador e radical, em que o primeiro está ligado às classes dominantes e o segundo a classes subalternas. O conceito Gramsciano de intelectual, permitirá uma reflexão sobre a função social do trabalho que o professor desenvolverá, podendo corresponder tanto as mudanças e transformações bem como para a manutenção e reprodução da sociedade dominante (GIROUX, 1992; 1997). Segundo Rodrigues (1998):

O intelectual transformador deve ser entendido como aquele cujas atividades se fundamentam em um discurso moral e ético pautado na preocupação com o sofrimento e com as lutas dos oprimidos; com o esforço por tornar o pedagógico mais político (inserindo a educação na esfera política e entendendo a escolarização como luta em torno da definição 
de significados e de relações de poder) e o político mais pedagógico (tratando seus estudantes como agentes críticos, questionando como o conhecimento é produzido e distribuído, utilizando o diálogo e procurando tornar o conhecimento curricular significativo, crítico e emancipador).

Moreira (1995) frente a essas concepções propõe que seja inserido a preocupação com as funções sociais do professor, na concepção de intelectual a dimensão mais acadêmica da "pesquisa em ação", sugerindo que o professor como intelectual é ao mesmo tempo um professor pesquisador de sua própria prática, assumindo assim o sentido reflexivo. Sugerindo, portanto:

[...] que os/as professores/as universitário/as, orientados/as por uma concepção de prática docente como contexto produtor e não apenas consumidor de conhecimentos, colaborem com os/as futuros/as professores/as em estudos que os/as ajudem a refletir sobre seus processos de ensino e de aprendizagem, estimulando-os a investigar seus desempenhos ou a participar de pesquisas já em andamento. (MOREIRA, 1995)

De acordo com o autor os professores (as) de Educação Física como intelectuais podem auxiliar no resgate para sua identificação e [re]significação do seu papel enquanto docente crítico, reflexivo, criativo e responsável no exercício da profissão, como também para compreensão e sensibilização do poder de natureza ideológica e econômica que essa atividade pode exercer sobre a sociedade. Giroux (1992) destaca que essa identificação da função do/a professor/a como intelectual "nos diferentes níveis do sistema escolar, em termos de sua política, da natureza de seus discursos e das funções pedagógicas que desempenham" está inerente na atividade docente.

A visão pedagógica deve se dá, pelas propostas e ações baseadas nos diálogos com os estudantes, os quais podem ser compreendidos como agentes críticos nesse processo de formação, bem como através da problematização e significação crítica dos conteúdos, conhecimentos e saberes, para que esses passem a ser emancipados no processo educacional. Assim, os estudantes poderão se reconhecer como agentes transformadores e críticos, com voz ativa nas vivências e contribuindo diretamente para as experiências pedagógicas em sala de aula, e ainda, relaciona-las com seu cotidiano (AZEVEDO et al., 2006).

Esse entrelace entre as atividades espontâneas do cotidiano dialogando com as atividades propostas pelos professores em sala segundo Schön (1992) podem acontecer de duas formas: "conhecimento na ação" e "reflexão na ação", a primeira relaciona-se com o conhecimento do cotidiano não sistematizado, espontâneo, natural e interiorizado, o qual não precede a ação. A segunda refere-se com a reflexão no momento da ação, quanto estamos realizando uma atividade, diálogo e/ou prática, ou seja, é uma análise da situação vivida no momento que nos encontramos envolvidos. Para o autor, o processo de reflexão na ação, transforma o profissional/docente em um pesquisador na sua prática. Essa teorização explicitada por Schön tem uma forte aproximação com a proposta por Stenhouse (1975), o qual destaca: "o professor não depende de teorias e técnicas preestabelecidas ele cria uma nova maneira de ver o problema". De acordo com o texto:

A prática constitui-se, desse modo, um processo que se abre não só para a resolução de problemas de acordo com determinados fins, mas à reflexão sobre quais devem ser os fins, qual o seu significado concreto em situações complexas conflituosas. E que[...] os processos de reflexão acabam sendo fonte de novos conflitos e discussões em torno dos limites que, para a compreensão e ação, as instituições e as práticas sociais colocam em relação aos problemas profissionais. (CONTRERAS, 2012)

Stenhouse, em seus escritos, percebe o professor com autonomia na seleção e trato com os 
conteúdos escolares da sua área de atuação, pois essa ação deve observar as demandas dos sujeitos ali inseridos, valorizando a pesquisa sobre a prática em educação, assim, "[...] o professor não depende das técnicas, regras e receitas derivadas de uma rotina externa, nem das prescrições impostas do exterior da administração ou pelo esquema preestabelecido no manual escolar" (GOMÉZ, 1992). O pensar e propor novos saberes a partir das suas experiências práticas e da sua investigação em sala de aula, possibilita aos docentes uma maior apropriação dos conhecimentos e do seu papel no exercício da profissão.

Contreras (2012) quando escreve sobre o professor como pesquisador, podemos perceber alguns pontos ligando aos de Schön e Stenhouse. Em especial quanto Stenhouse descreve o ensino como uma arte, pensando nos professores (as) que melhorem sua "arte" por meio da experimentação e análise crítica do seu exercício, expressando assim certos valores na busca por melhoria na sua própria prática de ensino.

Contreras (2012), faz uma ressalva importante dentro desse processo, em que observa "o professor pesquisador de sua própria prática transforma-a em objeto de investigação, buscando aprimorá-la. Como o currículo é a expressão da prática, é ele o elemento de reconstrução para que haja reconstrução da ação do professor". Sendo assim, ao considerarmos as singularidades de cada situação educacional em que vivenciamos, compreendendo que cada caso deva ser visto como único, e que as circunstâncias em que são presenciadas no processo educativo, tem influências e determinação na solução final, e ainda, para o "processo" e não para o "produto" da educação, pois "[...] os valores educativos representam aspirações e não conquistas" (CONTRERAS, 2012).

Tanto Schön como Stenhouse, em seus escritos no tocante as concepções do/a professor/a pesquisador/a, para as fundamentações pautadas na racionalidade prática aristotélica. Que segundo Contreras (2012) o fundamento aristotélico tem diferença clara para o significado das atividades 'técnicas' e para as atividades 'práticas'.

As técnicas se dirigem à produção para se obter como resultado coisas que são diferentes dele própria. As práticas se dirigem a realizar na própria ação os valores que se consideram corretos para ela. Segundo a ética aristotélica, a educação é um tipo de atividade prática quando é dirigida para a realização de qualidades intrínsecas ao próprio processo educativo. (CONTRERAS, 2012)

Assim, Contreras (2012), traz uma crítica da formação positivista, como o agente inabilitador para os professores. Em que o imprevisto, a incerteza, a dubiedade e as diversas situações de conflitos não sejam deliberadas, refletidas e ressignificadas na sala de aula, para que tudo seja realizado em conformidade como os "protocolos". Essas habilidades, de reflexão na ação, que os professores (as) deveriam passar e serem orientados para observar e experenciar esses dilemas durante sua formação inicial e prática docente. Pois o papel dos professores (as) de Educação Física, não pode ser restringido a aplicação de técnicas no ensino dos conteúdos, o docente é um ser humano - cidadão, o qual teoricamente, prepara e forma outros cidadãos, em seu processo de humanização para o exercício e reconhecimento da sua cidadania na sociedade onde está inserido.

\section{CONCLUSÕES}

A formação dos professores deve contemplar habilidades e competências necessárias para o 
exercício da docência. Essas competências faram com que o professor consiga fazer adaptações dentro do processo de ensino. Assim, as concepções teóricas, metodológicas, práticas filosóficas e epistemológicas da área, além das características políticas, culturais, econômicas e sociais desse sujeito em formação e da sociedade devem estar presentes durante todo o processo de formação.

Essa formação inicial só será possível, quando a universidade, professores formadores e escola, conseguirem atuar juntos, associando os referenciais e concepções para essa formação, levando em conta a figura, concepção e o real papel do professor pesquisador, auxiliando os novos profissionais à terem um olhar mais apurado e sensibilizado para o mundo social, para os sujeitos, para as possibilidades, dilemas, perspectivas e expectativas de uma sociedade melhor a todos. Não negando os conhecimentos técnicoscientíficos das matrizes de formação dos professores de Educação Física, mas a inserção de discursos acadêmicos científicos, epistemologias, filosóficos e políticos em sua formação.

Os profissionais de Educação Física na sua formação inicial, precisam parar e refletir sobre o seu campo de atuação, para que possam compreender que, em sua formação e atuação, o professor-reflexivo e professor-pesquisar cabe em todas as ações teóricas e práticas, em diálogo permanente com as novas metodologias. Mesmo que essa ideia seja tensiva ou paradoxal, a relação teoria e prática, acima de tudo, é um ponto de ligação para o professor como intelectual, consiga observar, pensar, refletir, propor e intervir na ação, e ainda tudo isso deve acontecer sempre com a precaução e para a valorização da sociedade de maneira geral entre o ser humano e espaço.

\section{REFERÊNCIAS}

AZEVEDO, A. C. B.; MALINA, A.. O professor de educação física como um intelectual transformador: apontamentos preliminares. In: ENCONTRO FLUMINENSE DE EDUCAÇÃO FíSICA ESCOLAR, 10. Anais. Niterói: UFF, 2006. p.259-263.

BRACHT, V.. Educação Física \& Ciência: cenas de um casamento (in)feliz. Revista Brasileira de Ciência do Esporte, v. 22, n.1, 2000

CONTRERAS, J.. O docente como profissional reflexivo. In: CONTRERAS, J.. A autonomia de professores. 2 ed. São Paulo: Cortez, 2012. p.117-146.

GÓMEZ, A. P.. O pensamento prático do professor: A formação do professor como profissional reflexivo. In: NÓVOA, A.. Os professores e a sua formação. Lisboa: Dom Quixote, 1992. p.93-115.

GIROUX, H.. Escola Crítica e Política Cultural. São Paulo: Cortez, 1992.

GIROUX, H.. Os Professores como Intelectuais. Rumo a uma Pedagogia Crítica da Aprendizagem. Porto Alegre: Artes Médicas, 1997.

LAURENCE, B.. Análise de conteúdo. São Paulo: 70, 2011.
MOREIRA, A. F.. O currículo como política cultural e a formação docente. In: SILVA, T. T.. Territórios contestados: o currículo e os novos mapas políticos e culturais. Petrópolis: Vozes, 1995.

NÓVOA, A.. Os professores e sua formação. Lisboa: Dom Quixote, 1992.

RODRIGUES, A. T.. A questão da formação de professores de educação física e a concepção de professor enquanto intelectual - reflexivo - transformador. Rev. Pensar a Prática, v.1, p.48-58, 2006.

SCHON, D. A.. Formar professores como profissionais reflexivos. In: NÓVOA, A.. Os professores e a sua formação. Lisboa: Dom Quixote, 1992.

STENHOUSE, L.. An introduction to curriculum research and development. Londres: Heinemann, 1975.

STENHOUSE, L.. Investigación y desarrollo del curriculum. Madrid: Morata, 1991.

TESSER, G. J.. Principais linhas epistemológicas contemporâneas. Educar em Revista, v.10, p.91-98, 1994.

A CBPC - Companhia Brasileira de Produção Científica (CNPJ: 11.221.422/0001-03) detém os direitos materiais desta publicação. Os direitos referem-se à publicação do trabalho em qualquer parte do mundo, incluindo os direitos às renovações, expansões e disseminações da contribuição, bem como outros direitos subsidiários. Todos os trabalhos publicados eletronicamente poderão posteriormente ser publicados em coletâneas impressas sob coordenação da Sustenere Publishing, da Companhia Brasileira de Produção Científica e seus parceiros autorizados. Os (as) autores (as) preservam os direitos autorais, mas não têm permissão para a publicação da contribuição em outro meio, impresso ou digital, em português ou em tradução. 